\title{
Uniportal VATS right apical segmentectomy (S1): a case report and the surgical technique
}

\author{
Jean H. T. Daemen ${ }^{1,2}$, Karel W. E. Hulsewé ${ }^{1}$, Yvonne L. J. Vissers ${ }^{1}$, Erik R. de Loos $^{1}$ \\ ${ }^{1}$ Division of General Thoracic Surgery, Department of Surgery, Zuyderland Medical Center, Heerlen, The Netherlands; ${ }^{2}$ Faculty of Health, \\ Medicine and Life Sciences (FHML), School for Oncology and Developmental Biology (GROW), Maastricht University, Maastricht, The \\ Netherlands \\ Correspondence to: Erik R. de Loos, MD. Division of General Thoracic Surgery, Department of Surgery, Zuyderland Medical Center, Henri \\ Dunantstraat 5, 6419 Heerlen, The Netherlands. Email: e.deloos@zuyderland.nl.
}

\begin{abstract}
Lobectomy has long been considered the standard procedure for early-stage non-small cell lung cancer. However, the interest in sub-lobar resections (i.e., segmentectomy) is increasing. Especially to be applied in patients with small tumors and marginal cardiopulmonary function. Yet, performing a segmentectomy through video-assisted thoracoscopic surgery (VATS) may be technically challenging, and even more challenging if performed through a uniportal approach. The objective of the current study is to describe and visualize the surgical technique of uniportal thoracoscopic segmentectomy by means of a case report. We present the case of a 58-year-old female in whom $18 \mathrm{~F}$-deoxyglucose positron emission tomography (FDG-PET)-computed tomography (CT) showed a 17-millimeter metabolically active lesion in segment 1 (S1; cTNM, cT1bN0M0 stage IA2). The patient was scheduled for a uniportal VATS right apical segmentectomy of S1 with additional mediastinal lymph node resection. The case and surgical technique were described and visualized. The surgical steps included adhesiolysis, dissection of the hilar structures, exposure and subsequent stapling of the A1 and V1a branch, exposure of the B1 bronchus branch and confirming exclusion of B1 prior to stapling, marking of the intersegmental planes with the use of indocyanine green and near-infrared fluorescence, stapling of the intersegmental parenchyma and an additional mediastinal lymph node resection. The recovery was uneventful.
\end{abstract}

Keywords: Case report; video-assisted thoracoscopic surgery (VATS); segmentectomy; uniportal

Received: 26 May 2021; Accepted: 01 September 2021; Published: 20 April 2022.

doi: 10.21037 /jovs-21-31

View this article at: https://dx.doi.org/10.21037/jovs-21-31

\section{Introduction}

Lobectomy has long been considered the standard procedure for early-stage non-small cell lung cancer. However, the interest in sub-lobar resections (i.e., segmentectomy) is increasing. Especially to be applied in patients with small tumors (i.e., smaller than two centimeters) and marginal cardiopulmonary function. Yet, performing a segmentectomy through videoassisted thoracoscopic surgery (VATS) may be technically challenging, and even more challenging if performed through a uniportal approach. The objective of the current study is to describe and visualize the surgical technique of uniportal thoracoscopic segmentectomy by means of a case report.

We present the following case in accordance with the CARE reporting checklist (available at https://jovs. amegroups.com/article/view/10.21037/jovs-21-31/rc).

\section{Case presentation}

We present the case of a 58-year-old smoking female with

\footnotetext{
$\wedge$ ORCID: 0000-0002-4878-3951.
} 


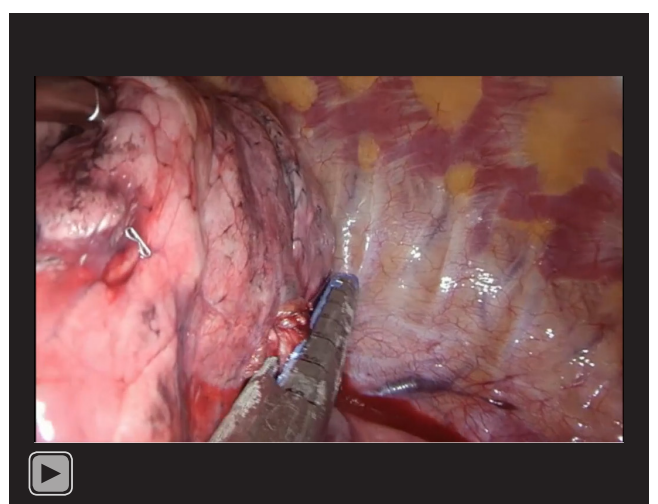

Video 1 Video demonstrating the surgical technique for segmentectomy of S1 (right lung) through uniportal video-assisted thoracoscopic surgery.

a body mass index of $33 \mathrm{~kg} / \mathrm{m}^{2}$, and a history of obstructive sleep apnea syndrome and hypercholesterolemia. She visited our pulmonology outpatient clinic with a request for follow-up after the incidental finding of a 13-millimeter irregular lung lesion in the right upper lobe, one-and-ahalf years earlier in another hospital abroad. Follow-up chest computed tomography (CT) demonstrated modest growth. Cytologic sampling using bronchoscopy was inconclusive. Subsequent $18 \mathrm{~F}$-deoxyglucose positron emission tomography (FDG-PET)-CT showed the known lesion in segment 1 (S1) which was metabolically active $\left(\mathrm{SUV}_{\max }: 3.7\right)$ and measured 17 -millimeter in diameter (cTNM, cT1bN0M0 stage IA2). Pulmonary function tests through spirometry and body plethysmograph yielded a pneumonectomy as maximum to be resected volume (FEV 1 : 92\%, TLCO: 85\%). The patient was scheduled for a uniportal VATS right apical segmentectomy of S1 with additional mediastinal lymph node resection.

The recovery was uneventful. The thoracic tube was removed on the first postoperative day and the patient was discharged the day thereafter. The final pathological diagnosis was pT1bPL0 acinar adenocarcinoma with a maximum diameter of 11 millimeters (the margins all around were more than 2 centimeters free), stage IA2, based on which the patient was enrolled into a follow-up program.

All procedures performed in this study were in accordance with the ethical standards of the institutional and/or national research committee(s) and with the Helsinki Declaration (as revised in 2013). Written informed consent was obtained from the patient for publication of this case report and accompanying images. A copy of the written consent is available for review by the editorial office of this journal.

\section{Surgical technique}

The surgical technique is shown in Video 1. Prior to surgery, prophylactic cefazolin was administered. The operation was performed under general anesthesia using a doublelumen endotracheal tube to selectively exclude the right lung from ventilation. The patient was placed in the left lateral recumbent position and a three-centimeter utility incision was made in the fifth intercostal space (mid axillary line). Access to the thoracic cavity was obtained and an Alexis wound protector (Applied Medical, CA, USA) was applied. A 10-millimeter, 30-degree high definition videothoracoscope was inserted. Adhesiolysis of adhesions between the lung and anterior chest wall was performed using Harmonic shears (Ethicon, Johnson\&Johnson, Amersfoort, The Netherlands). After visualization of the phrenic nerve, the mediastinal pleura was opened, and hilar structures were dissected. The pulmonary artery and superior pulmonary vein were subsequently identified. First, the anterior trunk of the pulmonary artery was distally dissected to expose the segmental branches. Branch A1 was identified and stapled using the Echelon powered vascular stapler (PVS; Ethicon, Johnson \& Johnson, Amersfoort, The Netherlands). White (stapler height of 1.0 millimeters), blue (height: 1.5 millimeters) and green (height: 2.0 millimeters) stapler cartridges were respectively used for vascular structures, parenchyma and bronchus. Secondly, the superior pulmonary vein was distally dissected and branch V1a was stapled. V1b was spared since it also facilitates venous return from segment 3 (S3). Nodal station 12 was resected to obtain space and for staging reasons. After dissection of the right upper lobe bronchus, the B1 bronchus branch was exposed and clamped. The right lung was inflated to confirm air passage for segment 2 (S2) and S3 while confirming exclusion of S1. After confirmation of anatomy, B1 was stapled using the powered Echelon60 stapler (Ethicon, Johnson \& Johnson, Amersfoort, The Netherlands), whereafter indocyanine green was administered intravenously $(7.5 \mathrm{mg})$. Using near-infrared fluorescence (Visera Elite II system, Olympus, Tokyo, Japan) the intersegmental planes were delineated and marked by diathermy whereupon the parenchyma was stapled at the intersegmental plane under thoracoscopic guidance. Presence of the lesion in the specimen was confirmed by palpation. In 
addition, the right-sided paratracheal and subcarinal and paraesophageal (i.e., station $2 \mathrm{R}, 4 \mathrm{R}, 7$ and 8 ) mediastinal lymph nodes were resected. The thoracic cavity was flushed with distilled water and a single-shot multilevel intercostal nerve block was administered. The right lung was reinflated under thoracoscopic guidance and a 28 French chest tube was left in place through the same incision. The total duration of surgery, from incision to closure, was 88 minutes with an estimated blood loss of 50 milliliters.

\section{Discussion}

The present report described the case of a patient who underwent a segmentectomy of S1 through a uniportal VATS approach. The primary advantage of sub-lobar resections, such as a segmentectomy, over conventional lobectomies is the sparing of parenchyma which offers better functional preservation compared with lobectomy (1). On its turn this broadens the criteria for anatomical resection which can consequently also be offered to patients with marginal cardiopulmonary function. However, oncologic outcomes may be at stake and has been a topic of much debate. Despite final conclusions on oncological outcomes will only be produced by two randomized controlled trials in the coming years $(2,3)$, a meta-analysis dating from 2017 supports the idea that patients who underwent a segmentectomy have similar survival outcomes than those of patients who received lobectomy for early-stage non-small cell lung carcinoma (4). Though, this only counts for tumors which are 2 centimeters in size or smaller. For tumors larger than 2 centimeters, lobectomy is generally favored (5).

Conventionally VATS is performed through a multiport approach, however, striving for minimal surgical trauma while maximizing efficacy, uniportal VATS has been introduced. The latter is associated with comparable operation times, but significantly lower blood loss, a significantly shorter duration of chest tube drainage and shorter hospital stay (6). Though it must be noted that these outcomes also depend on the complexity of the segmentectomy (7). In addition, although uniportal VATS is often technically more challenging, Xie and colleagues demonstrated that the surgical approach (i.e., uniportal versus multiportal) is not an independent risk factor for disease-free survival or overall survival among patients who underwent a thoracoscopic segmentectomy (7), thereby confirming the oncological safety of uniportal VATS segmentectomies for primary lung cancer.

Apart from the surgical approach used, different methods exist to identify the intersegmental borders, including the inflation-deflation method, selective resected segmental inflation, near-infrared fluorescence in combination with intravenous indocyanine green injection, endobronchial dye injection as well as three-dimensional $\mathrm{CT}$ in combination with virtual assisted lung mapping (8). The former, the inflation-deflation method is the conventional technique to delineate the intersegmental plane, however, limited by collateral ventilation which makes delineation unreliable. This phenomenon, which occurs through the canals of Lambert, the pores of Kohn and the direct airway anastomosis (9) was also observed in the present case (see Video 1), inflating the lung to confirm air passage for S2 and S3 while confirming exclusion of S1. In comparison to the conventional method, delineation using intravenous indocyanine green is not affected by collateral ventilation nor prone to failure in patients with emphysema. In addition, since no inflation is required, adequate thoracoscopic view is guaranteed. Success rates over 95\% are being described for the indocyanine green method (10-12). However, the dye and its equipment required for visualization are more costly.

In conclusion, we have described the case of a patient who underwent a segmentectomy of S1 through a uniportal VATS approach, moreover, visualizing and providing a detailed description of the surgical technique aiming to guide future surgeons on this specific segmentectomy.

\section{Acknowledgments}

Funding: None.

\section{Footnote}

Provenance and Peer Review: This article was commissioned by the Guest Editor (Michel Gonzalez) for the series "VATS Segmentectomy" published in Fournal of Visualized Surgery. The article has undergone external peer review.

Reporting Checklist: The authors have completed the CARE reporting checklist. Available at https://jovs.amegroups. com/article/view/10.21037/jovs-21-31/rc

Peer Review File: Available at https://jovs.amegroups.com/ article/view/10.21037/jovs-21-31/prf 
Conflicts of Interest: All authors have completed the ICMJE uniform disclosure form (available at https://jovs. amegroups.com/article/view/10.21037/jovs-21-31/coif). The series "VATS Segmentectomy" was commissioned by the editorial office without any funding or sponsorship. The authors have no other conflicts of interest to declare.

Etbical Statement: The authors are accountable for all aspects of the work in ensuring that questions related to the accuracy or integrity of any part of the work are appropriately investigated and resolved. All procedures performed in this study were in accordance with the ethical standards of the institutional and/or national research committee(s) and with the Helsinki Declaration (as revised in 2013). Written informed consent was obtained from the patient for publication of this case report and accompanying images. A copy of the written consent is available for review by the editorial office of this journal.

Open Access Statement: This is an Open Access article distributed in accordance with the Creative Commons Attribution-NonCommercial-NoDerivs 4.0 International License (CC BY-NC-ND 4.0), which permits the noncommercial replication and distribution of the article with the strict proviso that no changes or edits are made and the original work is properly cited (including links to both the formal publication through the relevant DOI and the license). See: https://creativecommons.org/licenses/by-nc-nd/4.0/.

\section{References}

1. Harada H, Okada M, Sakamoto T, et al. Functional advantage after radical segmentectomy versus lobectomy for lung cancer. Ann Thorac Surg 2005;80:2041-5.

2. Blasberg JD, Pass HI, Donington JS. Sublobar resection: a movement from the Lung Cancer Study Group. J Thorac Oncol 2010;5:1583-93.

3. Nakamura K, Saji H, Nakajima R, et al. A phase

doi: $10.21037 /$ jovs-21-31

Cite this article as: Daemen JHT, Hulsewé KWE, Vissers YLJ, de Loos ER. Uniportal VATS right apical segmentectomy (S1): a case report and the surgical technique. J Vis Surg 2022;8:18.
III randomized trial of lobectomy versus limited resection for small-sized peripheral non-small cell lung cancer (JCOG0802/WJOG4607L). Jpn J Clin Oncol 2010;40:271-4.

4. Bedetti B, Bertolaccini L, Rocco R, et al. Segmentectomy versus lobectomy for stage I non-small cell lung cancer: a systematic review and meta-analysis. J Thorac Dis 2017;9:1615-23.

5. Bao F, Ye P, Yang Y, et al. Segmentectomy or lobectomy for early stage lung cancer: a meta-analysis. Eur J Cardiothorac Surg 2014;46:1-7.

6. Lee J, Lee JY, Choi JS, et al. Comparison of Uniportal versus Multiportal Video-Assisted Thoracoscopic Surgery Pulmonary Segmentectomy. Korean J Thorac Cardiovasc Surg 2019;52:141-7.

7. Xie D, Wu J, Hu X, et al. Uniportal versus multiportal video-assisted thoracoscopic surgery does not compromise the outcome of segmentectomy. Eur J Cardiothorac Surg 2021;59:650-7.

8. Andolfi M, Potenza R, Seguin-Givelet A, et al. Identification of the intersegmental plane during thoracoscopic segmentectomy: state of the art. Interact Cardiovasc Thorac Surg 2020;30:329-36.

9. Spencer H. Pathology of the lung. Vol. 1. 4th edition. Oxford: Pergamon Press Ltd.,1985.

10. Guigard S, Triponez F, Bédat B, et al. Usefulness of nearinfrared angiography for identifying the intersegmental plane and vascular supply during video-assisted thoracoscopic segmentectomy. Interact Cardiovasc Thorac Surg 2017;25:703-9.

11. Mun M, Okumura S, Nakao M, et al. Indocyanine green fluorescence-navigated thoracoscopic anatomical segmentectomy. J Vis Surg 2017;3:80.

12. Pischik VG, Kovalenko A. The role of indocyanine green fluorescence for intersegmental plane identification during video-assisted thoracoscopic surgery segmentectomies. J Thorac Dis 2018;10:S3704-11. 